This is an author produced version of a paper published in Stress and Health. This paper has been peer-reviewed but does not include the final publisher proof-corrections or journal pagination.

Citation for the published paper:

Muhonen, Tuija; Torkelson, Eva. (2004). Work locus of control and its relationship to health and job satisfaction from a gender perspective. Stress and Health, vol. 20, issue 1, p. null

URL: https://doi.org/10.1002/smi.994

Publisher: Wiley

This document has been downloaded from MUEP (https://muep.mah.se) / DIVA (https://mau.diva-portal.org). 


\title{
Work locus of control and its relationship to health and job satisfaction from a gender perspective
}

\author{
TUIJA MUHONEN ${ }^{1}$ \\ School of Technology and Society, Malmö University, Sweden \\ EVA TORKELSON \\ Department of Psychology, Lund University, Sweden
}

Citation: Muhonen, T., \& Torkelson, E. (2004). Work locus of control and its relationship to health and job satisfaction from a gender perspective. Stress and Health, 20(1), 21-28.

${ }^{1}$ Ph.D. Tuija Muhonen, School of Technology and Society, Malmö University, SE-205 06 Malmö, Sweden. E-mail: tuija.muhonen@ts.mah.se. Phone: + 464066571 23. Fax: + 46406657320. 


\title{
Work locus of control and its relationship to health and job satisfaction from a gender perspective
}

\begin{abstract}
Summary
With its focus on gender, the aim of this study was to investigate the role of work locus of control (WLC) for job satisfaction and health in the context of occupational stress. Data were collected from 281 women and men at both managerial and non-managerial level in a Swedish telecom company. As hypothesized, external WLC was positively related to stressors and health symptoms, whereas it was negatively related to job satisfaction. These results applied for both women and men. Even though ANOVAS did not show a gender difference in WLC, the results of the hierarchical multiple regression analyses indicated that WLC was a significant predictor of both health symptoms and job satisfaction, but only for women. Besides these main effects WLC also acted as a moderator in the stress-health relationship for women. This indicates that separate analyses for women and men are needed in order to investigate potential gender differences that might otherwise go unnoticed.
\end{abstract}

\section{Key Words}

work locus of control, gender, health, job satisfaction 


\section{Introduction}

Stress can be viewed as a dynamic transactional process according to Lazarus and Folkman (1984). Individuals experience stress in situations where they perceive that the demands in the environment exceed their capacity do deal with them. The stress process can lead to different forms of strain affecting, e.g. individuals' well-being and job satisfaction (Lu, Kao, Cooper \& Spector, 2000; Kirkcaldy, Shephard \& Furnham, 2002). In studies concerning occupational stress there has been an increasing interest in the potential role of generalized control beliefs (Daniels \& Guppy, 1994). Individuals who believe they themselves can control the reinforcements through their behavior are regarded as having internal locus of control, whereas individuals who have external locus of control believe that external forces such as luck and fate control the reinforcements of their behavior (Rotter, 1966).

Locus of control is one of the most cited constructs and Rotter's I-E (internalexternal) scale is widely used in different studies (Antonovsky, 1991; Furnham \& Steele, 1993). Locus of control can be viewed either as a uni- or multidimensional construct. Uni-dimensionality refers to a global control belief, whereas multidimensionality indicates that people may differ in their locus of control beliefs regarding different areas of life, e.g. achievement and health outcomes (Hewitt \& Flett, 1996). Viewing locus of control as multidimensional requires the use of domain-specific measures instead of a global measure. During the past decade several scales have also been developed to measure control beliefs in specific domains (18 scales according to Lefcourt, 1992).

Work locus of control scale (WLCS), a domain specific measure of locus of control in organizational settings, was developed by Spector (1988). Locus of control beliefs measured by the scale include rewards or outcomes such as promotions, salary increases and general career progress (Spector, 1988). Several studies have shown that there is an overlap between Rotter's and Spector's measures with correlations ranging between .49 and .63 (Blau, 1993; Cvetanovski \& Jex, 1994; Spector, 1988).

The domain specific measures are generally considered better predictors than the global measure of locus of control (Lefcourt, 1992). This claim is supported by studies, which have indicated that WLCS is a better predictor of work behavior than the generalized measure of locus of control (Blau, 1993; Orpen, 1992). WLCS has been used in several studies concerning e.g. different performance dimensions (Blau, 1993), unemployment (Cvetanovski \& Jex, 1994), stress and well-being (Daniels \& Guppy, 1994; Lu et al, 2000; Spector \& O’Connell, 1994) and selection interviews (Silvester, AndersonGough, Anderson, \& Mohamed, 2002).

According to earlier studies individuals with internal WLC (WLC) tend to report higher well-being (Spector et al., 2001) and experience less stress at work (Lu et al., 2000; Orpen, 1992; Ross, 1991). Furthermore, stressors seem to have less effect on well-being for individuals who have internal locus of control (Daniels \& Guppy, 1994; Lu et al., 2000). Several studies have also revealed that internal WLC is positively related to different organizational outcomes such as motivation, job performance, job satisfaction, perception of organizational climate and organizational commitment (Blau, 1993; Furnham \& Drakeley, 1993; Lu et al., 2000; Orpen, 1992; Ross, 1991). The results of Cvetanovski and Jex's study (1994) showed that unemployed people with internal locus of control were more satisfied with life and also felt better both psycho- 
logically and physically than externals. Besides studying the main effects of WLC as reported above, also the moderating effects of WLC in the stress-health relationship have been investigated (Lu et al., 2000; Moyle \& Parkes, 1999). However, the results have been inconclusive. Lu et al., (2000) demonstrated that WLC can act as a moderator, whereas Moyle \& Parkes (1999) found that WLC had neither direct, nor moderating influence on psychological strain.

The theoretical background for the locus of control construct comes from social learning theory (Rotter, 1966). According to this theory a reinforcement strengthens an expectancy that a particular behavior or event will be associated with that reinforcement. Rotter (1966) assumed that these kinds of expectancies or beliefs could be generalized to different situations and therefore affect the behavioral choices an individual makes. Considering its theoretical basis in social learning, it could be argued that WLC can also change as a result of new learning experiences. Furnham and Drakeley (1993) maintain that those individuals who have little access to power, opportunity or material advantage will probably develop external expectancies. This implies that the individual's locus of control beliefs could develop differently due to environmental factors. Organizational level, i.e. having a managerial position might be one of the factors that could influence employees' WLC beliefs. Those who have managerial positions could develop more internal WLC beliefs.

Research on gender and general locus of control beliefs has revealed inconsistent results. Some studies indicate women to be more externally oriented than men (Gurin, Gurin and Morrison, 1978; Itzhaky \& Ribner, 1999); some have shown contrary results (Jayaratne \& Ivey, 1983); whereas others have found no gender differences in locus of control (Holder \& Vaux, 1998; Lengua \& Stormshak, 2000). When it comes to studies that have used Work locus of control scale (e.g. Blau, 1993; Orpen, 1992; Spector \& O'Connell, 1994) the aspect of gender has not been a primary issue. Since earlier psychological research has often been characterized by androcentricity, as pointed out e.g. by Greenglass (1993), it is important to include women's experiences in the studies. Gender is also a relevant variable considering the increase of women in the labor market in western societies (Davidson \& Burke, 2000). In Sweden e.g. nearly 50\% of the workforce consists of women (SCB, 2002). Yet, the labor market is segregated, which means that women are more often found at the lower organizational levels than men throughout Europe (Davidson \& Burke, 2000). Due to women's subordinate position in the labor market, it could be argued that gender differences in behavior might actually originate from differences in access to power.

In sum, many of the locus of control studies in work settings have not used WLCS, even though it is considered a better predictor of work behavior than the generalized measure of locus of control. Those studies that have used WLCS have not focused on gender and at the same time controlled for status differences between women and men. Women and men have often been studied in non-equivalent jobs and positions, therefore resulting in differences that might have been related to the status participants have in the organizations rather than their gender (Spielberger \& Reheiser, 1995).

The design of the current study, comparing women and men who worked with similar tasks and at the same organizational levels, enabled us to examine WLC from a gender perspective. The objective of this study was to investigate the role of WLC for job satisfaction and health in the context of occupational stress among women and men working at a sales division in a Swedish telecom company. It was hypothesized that 
external WLC would be positively related to stressors and health symptoms, whereas it would be negatively related to job satisfaction. Further, the moderating effect of WLC concerning health symptoms and job satisfaction were analyzed.

\section{Method}

\section{Participants and procedure}

Self-administered questionnaires were distributed by mail to 422 employees in a Swedish telecom company. A covering letter was enclosed informing about the purpose of the study and that participation was voluntary and anonymous. Questionnaires were returned anonymously in a stamped, self-addressed envelope. The studied telecom company develops internet based services and products to solve communication needs for organizations. All the managers (45 women and $67 \mathrm{men}$ ) in the sales division were included in the study. A random sample of 155 women and 155 men at the nonmanagerial level in the same division was selected by using personnel lists. Two reminders were sent to the participants and the final response rate was $67 \%$.

The group of participants consisted of 40 female managers, 60 male managers, 94 female non-managers and 85 male non-managers (two participants had not specified their gender). The average age of the participants was 43 years $(S D=9.07)$ and the majority of them (82\%) were married and nearly all (94\%) were working full-time. Altogether $37 \%$ of the participants had university education. There were significant gender differences in educational level $(F(1,261)=5.30, p<0.05)$, and in years of employment $(F(1,261)=5.80, p<0.05)$. Men had university education to a higher extent $(M=0.46, S D=0.50)$ than women $(M=0.29, S D=0.45)$, whereas women had been employed for a longer time in the company $(M=17.20, S D=11.57)$ than men $(M$ $=13.85, S D=12.50)$. There was also a significant difference in educational level between managers and non-mangers $(F(1,261)=34.86, p<.01)$. Non-managers had university education less frequently $(M=.25, S D=.43)$ than managers $(M=.60, S D=$ .49).

\section{Study variables}

Demographic characteristics included in the questionnaire were gender, age (a continuous variable), educational level ( $1=$ university degree or $0=$ not $)$, organizational level ( 1 = managerial position or $0=$ not), and years of employment (a continuous variable).

Work locus of control was assessed by a Swedish version (Muhonen, 1999) of Spector's (1988) WLCS. It contains 16 work-related items (e.g. job effort, getting a job, promotions) to which participants respond on a six-point scale from 1 (disagree very much) to 6 (agree very much). A sample item is "Promotions are usually a matter of good fortune." The scale has equal numbers of internally and externally worded items. Higher scores on WLCS indicate externality, which is also the case with Rotter's (1966) measure. The coefficient alpha of the scale in the present study was 0.86 , which is in accordance with other studies (Blau, 1993; Lu et al., 2000). The scores were skewed toward internality $(M=39.70)$. This is also consistent with previous studies e.g. Spector, 1988. Some researchers divide participants into either internals or externals, whereas 
others view the concept as a continuum ranging from high internal locus of control to high external locus of control (Cvetanovski \& Jex, 1994; Renn \& Vandenberg, 1991). The second strategy advocated by both Rotter (Renn \& Vandenberg, 1991) and P.E. Spector (personal communication, December 20, 2002), is also the one used in the current study.

Stressors were measured by 11 items concerning how often participants were facing different demands at work $(\alpha=.70)$. Items about different sources of stress, e.g. quantitative overload, and home-work conflict, were selected from Dallner, et al. (2000). The items were discussed with a group of employees and as a result modified in order to be relevant for the studied group. A sample item is "Is your work situation affected by poor planning?” Response alternatives ranged from 1 (= very rarely) to 4 (= very often).

Health symptoms were assessed by the Hopkins Symptom Checklist-25 (HSCL-25), (Derogatis, Lipman, Rickels, Uhlenhuth, \& Covi, 1974). HSCL consists of 25 items measuring symptoms such as headache, insomnia and anxiety $(\alpha=.94)$. Respondents rated the intensity of different symptoms on a scale ranging from 1 (= not bothered) to 4 (= extremely bothered).

Job satisfaction was measured by one-item global measure, namely "On the whole are you satisfied with your work"? Response alternatives ranged from 1 (= very rarely) to 4 (= very often).

\section{Results}

The number of participants varies in the different analyses, due to some missing values in the data. Since missing values were limited in number no replacement procedure was used. Default options in SPSS 11.5.1 were utilized in the analyses.

Two-way ANOVAs were carried out initially in order to investigate potential differences related to gender and organizational level. The results did not show any gender difference in $\operatorname{WLC}(F(1,261)=0.03, p>0.05)$. There was significant difference in WLC between managers and non-mangers $(F(1,261)=25.23 p<.01)$. Non-managers scored more towards internal WLC $(M=41.89, S D=10.91)$ when compared with managers $(M=35.76, S D=7.83)$. The two-way ANOVAS did not show any interaction effects for gender and organizational level.

\section{The main effect of WLC on health symptoms and job satisfaction}

Table I presents the correlations and descriptive statistics for all the variables in the study separately for women and men. The results of the correlation analyses are in line with our hypotheses. A significant positive relationship was found between stressors and WLC. Participants with higher values on WLC (external) also report higher levels of stress. External WLC was also significantly related to reporting of more health symptoms. WLC had a significant negative relationship to job satisfaction. This indicates that external WLC is associated with participants perceiving lower level of job satisfaction. The correlations were similar for both female and male participants.

$$
\text { Insert Table I near here }
$$


We were also interested in investigating the moderating effect of WLC on health symptoms and job satisfaction, when demographics and stressors were taken into consideration. Hierarchical multiple regression analyses were conducted using forced entry method (Licht, 1995). In order to reveal potential gender differences, separate analyses were run for women and men. Health symptoms and job satisfaction were used as dependent variables. Demographics, stressors, WLC and the interaction term stressors X WLC were used as independent variables in the multiple regression analyses.

At the first step the demographic variables: educational level, organizational level and years of employment were entered in the equation as control variables. On the second step stressors and WLC were entered into the equation. To test the interaction effect of stressors and WLC, the interactions term stressors X WLC was entered at the third step.

Insert Table II near here

Table II presents the results of the multiple hierarchical regression analyses predicting health symptoms separately for women and men. The results showed that none of the demographic variables contributed to increment in explained variance in health symptoms. Stressors seemed to be the strongest predictor of health symptoms for both women and men. The results also reveal that WLC contributed to explaining variance in health symptoms for women, but not for men. Further, the interaction term stressors X WLC had a significant relationship to women's health symptoms. Figure 1 illustrates the moderating effect for women (left) and the no moderating effect for men (right). The total model explained 39\% of the variance in women's health symptoms and $42 \%$ of men's health symptoms.

\section{Insert Figure 1 near here}

In Table III the results of the multiple hierarchical regression analyses predicting job satisfaction for women and men can be seen. The results showed that the years of employment was a significant factor for men's job satisfaction, indicating that men with more years of employment were more satisfied with their jobs.

\section{Insert Table III near here}

Stressors contributed significantly to job satisfaction for both women and men. WLC also contributed significantly, but only as regards women's job satisfaction. In contrast to the prediction of health symptoms, the total model fitted women $\left(R^{2}=.31\right)$ better than men $\left(R^{2}=.21\right)$ in predicting job satisfaction.

\section{Discussion}


The aim of the current study was to investigate WLC and its relationship to job satisfaction and health from a gender perspective. By comparing women and men who worked with similar tasks and at the same organizational levels, we were able to consider gender and organizational status simultaneously. The results of the two-way ANOVAS showed neither a gender difference in WLC, nor any interaction effects for gender and organizational level. However, non-managers reported more external locus of control beliefs, which implies that status in the organization can be central for WLC. This result is in line with Furnham and Drakeley (1993), who have pointed out that individuals with little access to power might develop external control beliefs.

In accordance with earlier studies (e.g. Daniels \& Guppy, 1994; Lu et al., 2000), external WLC was related to reporting of a greater amount of stress at work. WLC had a significant negative correlation with job satisfaction and a significant positive correlation with health symptoms, indicating that external WLC was associated with lower job satisfaction and more health symptoms. These findings are in line with earlier studies (Blau, 1993; Cvetanovski \& Jex, 1994; Furnham \& Drakeley, 1993). The correlations above were similar for both women and men.

The results of the multiple regression analyses corroborated that WLC was a significant predictor for both health and job satisfaction, but only for women. Further, an interaction effect of stressors X WLC was found to be significant concerning women's health. It appears that women who experience high level of stress and score towards externality in WLC also report health symptoms to a greater extent. These findings were unexpected since two-way ANOVAS failed to show any gender differences in WLC. Why the external WLC beliefs in combination with high level of stress appears to make women more vulnerable than men needs to be explored further in future studies. The results also indicate that separate analyses for women and men are needed in order to investigate potential gender differences that otherwise might not be noticed.

There are both strengths and limitations in the current study. The design of the study comparing women and men in similar tasks and organizational levels and in the same organization could be regarded as a strength. It is an advantage to conduct a study in one organization, since tasks and positions can differ between different organizations, thus making comparisons less reliable.

The strengths above have concomitant limitations. The relatively small total sample size and the fact that the data were collected from only one organization, limit the generalizability of the findings to other organizations. We measured job satisfaction with a single-item, a procedure that is debatable but can be regarded as an acceptable way to measure overall job satisfaction according to Wanous, Reichers \& Hudy (1997). Also, factors apart from WLC, e.g. coping strategies and social support, could influence the stress-health relationship either directly or indirectly (Bellman, Forster, Still \& Cooper, 2003; Daniels \& Guppy, 1994; Greenglass, 1993). Yet another limitation of the study is its cross-sectional design, which does not allow causal conclusions to be drawn on the basis of the results. There is need for longitudinal studies using multiple measures in order to further investigate WLC beliefs for women and men while controlling for organizational status and the types of tasks performed.

To summarize, external WLC was related to higher amounts of stress at work, lower job satisfaction and more health symptoms. Whether these associations are due to dispositional WLC beliefs or if WLC beliefs are formed by external factors e.g. power in the organization, as pointed out by Furnham and Drakeley (1993), needs yet to be 
investigated. Further, WLC emerged as a significant predictor for both health symptoms and job satisfaction for women, but not for men. WLC also acted as a moderator in the stress-health relationship for women. The findings call for additional studies exploring the relationship between WLC and gender, as well as how WLC beliefs might be influenced by situational factors, e.g. the organizational level of the participants.

\section{Acknowledgments}

We gratefully acknowledge the financial support for this research from AFA (Labor market insurance), a Swedish insurance company, grant PA 06:00. 


\section{References}

Antonovsky, A. (1991). The structural sources of salutogenic strengths. In C. L. Cooper, \& R. Payne (Eds.), Personality and stress: Individual differences in the stress process (pp. 67-103). Chichester: John Wiley \& Sons.

Bellman, S., Forster, N., Still, L., \& Cooper, C. L. (2003). Gender differences in the use of social support as a moderator of occupational stress. Stress and Health, 19, 45-58.

Blau, G. (1993). Testing the relationship of locus of control to different performance dimensions. Journal of Occupational and Organizational Psychology, 66, 125-138.

Cvetanovski, J., \& Jex, S. M. (1994). Locus of control of unemployed people and its relationship to psychological and physical well-being. Work \& Stress, 8(1), 60-67.

Dallner, M., Elo, A.-L., Gamberale, F., Hottinen, V., Knardahl, S., Lindström, K., Skogstad, A., \& Ørhede, E. (2000). Validation of the general Nordic questionnaire, QPSNordic, for psychological and social factors at work. Nord 2000:12. Copenhagen: Nordic Council of Ministers.

Daniels, K., \& Guppy, A. (1994). Occupational stress, social support, job control and psychological well-being. Human Relations, 47(12), 1523-1544.

Davidson, M. J., \& Burke, R. J. (2000). Women in management: Current research issues, Volume II. London: Sage.

Derogatis L. R., Lipman, R. S., Rickels, K., Uhlenhuth, E. H., \& Covi, L. (1974). The Hopkins symptom checklist (HSCL): A self-report symptom inventory. Behavioral Science, 19, 1-15.

Furnham, A., \& Drakeley, R. J. (1993). Work locus of control and perceived organizational climate. European Work and Organizational Psychologist, 3(1), 1-9.

Furnham, A., \& Steele, H. (1993). Measuring locus of control: a critique of general, children's, health- and work-related locus of control questionnaires. British Journal of Psychology, 84, 443-479.

Greenglass, E. R. (1993). Social support and coping of empoyed women. In B. C. Long, \& S. E. Kahn (Eds.), Women, work and coping (pp. 154-169). Montreal: McGillQueen's University Press.

Gurin, P., Gurin, G., \& Morrison, B. M. (1978). Personal and ideological aspects of internal and external locus of control. Social Psychology, 41 (4), 275-296.

Hewitt, P. L., \& Flett, G. (1996). In M. Zeidner, \& N. S. Endler (Eds.), Handbook of coping. Theory, research, applications (pp. 410-433). New York: John Wiley \& Sons.

Holder, J. C., \& Vaux, A. (1998). African American professionals: coping with occupational stress in predominantly white work environments. Journal of Vocational Behavior, 53(3), 315-333.

Itzhaky, H., \& Ribner, D. S. (1999). Gender, values and the work place: considerations for immigrant acculturation. International Social Work, 42(2), 127-138.

Jayaratne, S., \& Ivey, K. V. (1983). The world view of clinical social workers and some related gender differences. Journal of Social Service Research, 6(3/4), 75-87.

Kirkcaldy, B. D., Shephard, R. J., \& Furnham, A. F. (2002). The influence of type A behaviour and locus of control upon job satisfaction and occupational health. Personality and Individual Differences, 33, 1361-1371.

Lazarus, R. S., \& Folkman, S. (1984). Stress, appraisal, and coping. New York: Springer Publishing Company. 
Lefcourt, H. M. (1992). Durability and impact of the locus of control construct. Psychological Bulletin, 112(3), 411-414.

Lengua, L. J., \& Stormshak, E. A. (2000). Gender, gender roles, and personality: gender differences in the prediction of coping and psychological symptoms. Sex Roles, 43(11/12), 787-820.

Licht, M. H. (1995). Multiple regression and correlation. In L. G. Grimm \& P. R.

Yarnold (Eds.), Reading and understanding multivariate statistics. Washington, DC: American Psychological Ass., pp. 19-64.

Lu, L., Kao, S.-F., Cooper, C. L., \& Spector, P. E. (2000). Managerial stress, locus of control, and job strain in Taiwan and UK: a comparative study. International Journal of Stress Management, 7(3), 209-226.

Moyle, P., \& Parkes, K. (1999). The effect of transition stress: a relocation study. Journal of Organizational Behavior, 20, 625-646.

Muhonen, T. (1999). Women, career, and family. A study among managers in four different branches. Doctoral thesis, Department of Psychology, Lund University (In Swedish with English summary).

Orpen, C. (1992). The work locus of control scale as a predictor of employee attitudes and behaviour: a validity study. Psychology, A Journal of Human Behavior, 2(1), 3537.

Renn, R. W., \& Vandenberg, R. J. (1991). Differences in employee attitudes and behaviors based on Rotter's (1966) internal-external locus of control: are they all valid? Human Relations, 44(11), 1161-1178.

Ross, G. F. (1991). Correlates of work responses in tourist industry. Psychological Reports, 68, 1079-1082.

Rotter, J. B. (1966). Generalized expectancies for internal versus external control of reinforcement. Psychological Monographs, 80(1),1-28.

SCB (Statistics Sweden). (2002). På tal om kvinnor och män. [About women and men]. Örebro: Statistics Sweden.

Silvester, J., Anderson-Gough, F. M., Anderson, N. R., \& Mohamed, A. R. (2002). Locus of control, attributions and impression management in the selection interview. Journal of Occupational and Organizational Psychology, 75, 59-76.

Spector, P. E. (1988). Development of work locus of control scale. Journal of Occupational Psychology, 61, 335-340.

Spector, P. E., \& O'Connell, B. J. (1994). The contribution of personality traits, negative affectivity, locus of control and Type A to the subsequent reports of job stressors and job strains. Journal of Occupational and Organizational Psychology, 67, 1-11.

Spector, P. E., Cooper, C. L., Sanchez, J. I., O’Driscoll, M., Sparks, K., Bernin, P., et al. (2001). Do national levels of individualism and internal locus of control relate to well-being: an ecological level international study. Journal of Organizational Behavior, 22, 815-832.

Spielberger, C. D., \& Reheiser, E. C. (1995) Measuring occupational stress: The Job Stress Survey. In R. Crandall, \& P. L. Perrewé (Eds.) Occupational stress: A handbook (pp. 51-69). Washington, DC: Taylor \& Francis, Ltd.

Wanous, J. P., Reichers, A. E., \& Hudy, M. J. (1997). Overall job satisfaction: How good are single-item measures? Journal of Applied Psychology, 82(2), 247-252. 
Table I. Correlations and descriptive statistics for the study variables

$$
\text { Variable }
$$

1

2

3

4

5

6

7

\begin{tabular}{lcccccccr}
\hline 1. WLCS & - & $-.23^{* *}$ & .03 & $-.26^{* *}$ & $.33^{* *}$ & $-.48^{* *}$ & $.30^{* *}$ & 4 \\
2. Educational level & $-.21^{*}$ & - & -.30 & $.27^{* *}$ & -.07 & $.18^{*}$ & -.04 \\
3. Years of employment & .02 & $-.17^{*}$ & - & -.03 & .08 & .02 & -.01 & \\
4. Organizational level & $-.31^{* *}$ & $.39^{* *}$ & -.14 & - & .14 & .07 & .07 \\
5. Stressors & $.36^{* *}$ & -.12 & -.07 & -.05 & - & $-.40^{* *}$ & $.51^{* *}$ & 2 \\
6. Job satisfaction & $-.32^{* *}$ & .06 & $.19^{* *}$ & .03 & $-.35^{* *}$ & - & $-.36^{* *}$ & 3 \\
7. Health symptoms & $.38^{* *}$ & -.12 & .03 & -.14 & $.60^{* *}$ & $-.38^{* *}$ & - & 38 \\
\hline
\end{tabular}

Note. Spearman's rho (pairwise deletion of missing values). Correlations above the diagonal are for women and below the diagonal for men. $n=129-134$ for women ; $\mathrm{n}=$ 141-145 for men. $* p<.05$, ${ }^{* *} p<.01$. 
Table II. Results of hierarchical multiple regression analyses predicting health symptoms for women and men

\begin{tabular}{|c|c|c|c|c|c|c|}
\hline \multirow[b]{2}{*}{ Variables } & \multicolumn{3}{|c|}{ Women } & \multicolumn{3}{|c|}{ Men } \\
\hline & $\bar{\beta}$ & $F$ & $R^{2}$ & $\beta$ & $F$ & $R^{2}$ \\
\hline \multicolumn{7}{|l|}{ Step 1} \\
\hline Educational level & -.03 & & & -.00 & & \\
\hline Organizational level & .05 & & & -.06 & & \\
\hline Years of employment & -.07 & 0.22 & .01 & .03 & 1.22 & .03 \\
\hline \multicolumn{7}{|l|}{ Step 2} \\
\hline Stressors & $.39 * *$ & & & $.53 * *$ & & \\
\hline Work locus of control & $.24 * *$ & $11.47 * *$ & .33 & .12 & $18.66^{* *}$ & .41 \\
\hline \multicolumn{7}{|l|}{ Step 3} \\
\hline Stressors $\times$ WLC & $.27 * *$ & $12.50 * *$ & .39 & .10 & $15.98 * *$ & .42 \\
\hline
\end{tabular}

Note. Women: $n=124$; Men: $n=141^{*} p<.05$, ${ }^{* *} p<.01$. 
Table III. Results of hierarchical multiple regression analyses predicting job satisfaction for women and men

\begin{tabular}{|c|c|c|c|c|c|c|}
\hline \multirow[b]{2}{*}{ Variables } & \multicolumn{3}{|c|}{ Women } & \multicolumn{3}{|c|}{ Men } \\
\hline & $\beta$ & $F$ & $R^{2}$ & $\beta$ & $F$ & $R^{2}$ \\
\hline \multicolumn{7}{|l|}{ Step 1} \\
\hline Educational level & .10 & & & .10 & & \\
\hline Organizational level & .04 & & & -.05 & & \\
\hline Years of employment & .06 & 1.53 & .04 & $.23 * *$ & 3.78 & .08 \\
\hline \multicolumn{7}{|l|}{ Step 2} \\
\hline Stressors & $-.31 * *$ & & & $-.28 * *$ & & \\
\hline Work locus of control & $-.31^{* *}$ & 9.96 & .30 & -.15 & 7.26 & .21 \\
\hline Step 3 & & & & & & \\
\hline Stressors X WLC & -.12 & 8.74 & .31 & -.01 & 6.01 & .21 \\
\hline
\end{tabular}

Note. Women: $n=126$; Men: $n=141 .{ }^{*} p<.05$, ${ }^{* *} p<.01$. 

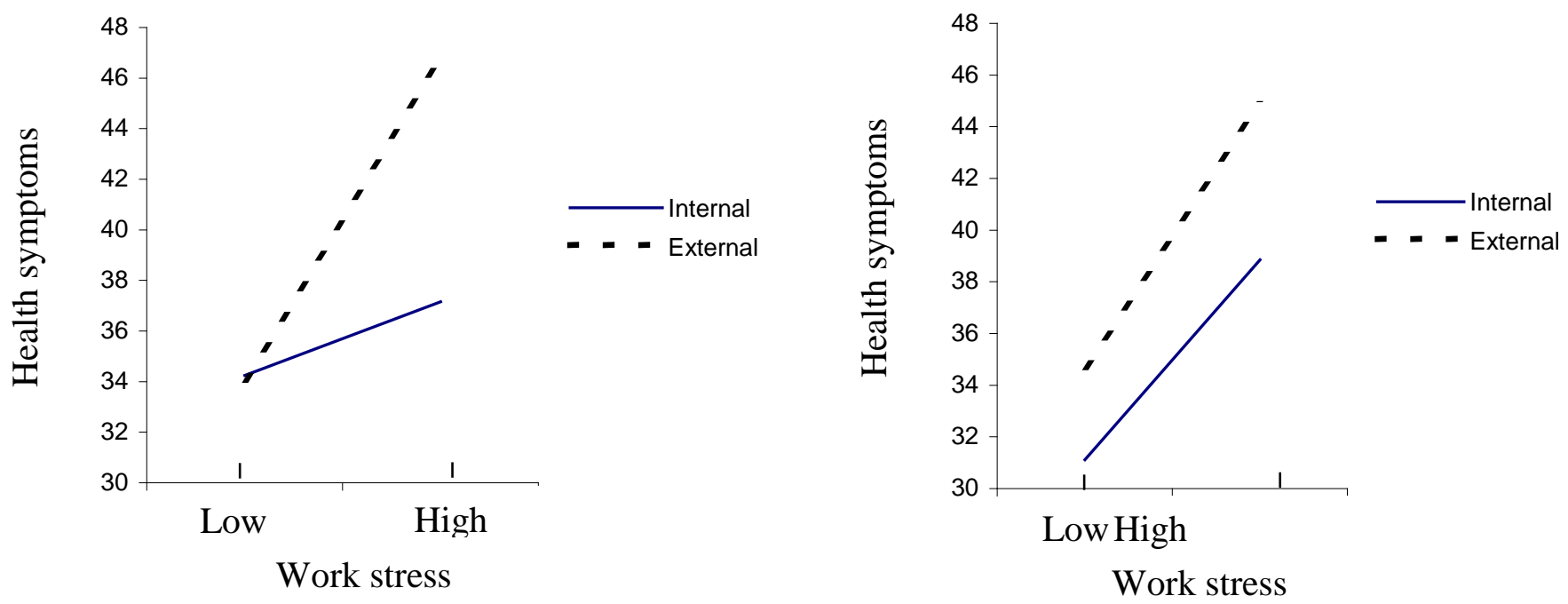

Figure 1. The moderating effect of WLC on the relationship between stressors and health symptoms for women (left) and no moderating effect for men (right) 